\title{
Evaluation of $\mathrm{IC}_{50}$ levels immediately after treatment with anticancer reagents using a real-time cell monitoring device
}

\author{
MAI HAZEKAWA, TAKUYA NISHINAKAGAWA, \\ TOMOYO KAWAKUBO-YASUKOCHI and MANABU NAKASHIMA
}

\begin{abstract}
Department of Immunological and Molecular Pharmacology, Faculty of Pharmaceutical Science, Fukuoka University, Jonan-ku, Fukuoka 814-0180, Japan
\end{abstract}

Received November 4, 2018; Accepted June 13, 2019

DOI: $10.3892 /$ etm.2019.7876

\begin{abstract}
A real-time cell-monitoring analysis (RTCA) system was previously developed based on the change in impedance when cells attach and spread in a culture dish coated with a gold microelectrode array. However, the potential applications of this system have not yet been fully demonstrated. The purpose of this study was to test the utility of the RTCA system to determine the cytotoxicity of four anticancer agents in carcinoma cells. The results were compared with those of the conventional WST-8 assay at the endpoint to determine the potential of the RTCA system as a new real-time assay method to evaluate cytotoxicity. iCELLigence was used as the RTCA system in this study. Suspensions of oral squamous cell carcinoma (OSCC) cell lines were seeded $\left(2 \times 10^{4}\right.$ cells/well) onto the E-plate (the culture plate of the iCELLigence system). After $24 \mathrm{~h}$ of culture, anticancer agents were added to each well, and changes in electrical impedance (cell index, CI) were recorded for another $72 \mathrm{~h}$ of culture. Cell proliferation was detected in real-time by the RTCA device in an automated, high throughput manner. Then, the $\mathrm{IC}_{50}$ profiles of the four anticancer agents were calculated based on the real-time cell index values. The results indicated that the RTCA system was useful in evaluating cytotoxic reactions immediately after the addition of the anticancer agents as it was able to record the data in real-time. Furthermore, the $\mathrm{IC}_{50}$ levels measured by the real-time assay were lower than those measured by the endpoint assay. Thus, RTCA systems can be used to evaluate chemotherapeutic agents in cancer cells as well as their side effects in normal cells.
\end{abstract}

Correspondence to: Dr Mai Hazekawa, Department of Immunological and Molecular Pharmacology, Faculty of Pharmaceutical Science, Fukuoka University, 8-19-1 Nanakuma, Jonan-ku, Fukuoka 814-0180, Japan

E-mail:mhaze@fukuoka-u.ac.jp

Key words: RTCA system, $\mathrm{IC}_{50}$, cytotoxicity, squamous cell carcinoma, anticancer reagent

\section{Introduction}

A real-time cell-monitoring analysis (RTCA) system was previously developed for continuous monitoring of adherent cell cultures (1). This label-free and non-invasive method is based on measurement of the electrical impedance (cell index, CI) between interdigitated regions on the base of tissue culture plates. The CI measurement provides quantitative information about the biological status of adherent cells. Actually, the meaning of $\mathrm{CI}$ is the number of survival cell on the surface of E-plate. These data include the cell number, viability, and morphology as a real-time profile (2-4). RTCA system is known to early detection device of cell reaction as a dynamic phenotype against some reagents (5).

In our previous study, imatinib cytotoxicity in oral squamous cell carcinoma (OSCC) was assessed using the WST-8 (5-[2,4-Bis(sodiooxysulfonyl)phenyl]-3-(2methoxy-4-nitrophenyl)-2-(4-nitrophenyl)-2H-tetrazole-3-ium) assay as an endpoint measurement (6), and then later with an RTCA system (7). Endpoint measurements by MTT (3-[4,5dimethylthiazol-2-yl]-2,5-diphenyltetrazolium bromide) and WST-8 assays are commonly used to evaluate cytotoxicity. However, such assays are limited by variations in the effects of different anticancer agents on different cell lines. Furthermore, $\mathrm{IC}_{50}$ values calculated by in vitro endpoint assays tend to be higher than the effective concentrations in vivo $(8,9)$.

In our previous study, the $\mathrm{IC}_{50}$ values measured by the RTCA system were lower than those measured by the WST- 8 assay, suggesting that the RTCA system can sensitively evaluate cytotoxicity and the influence of imatinib on cell adhesion. However, it is unclear whether evaluation of the $\mathrm{IC}_{50}$ values of other anticancer agents using the RTCA system would be useful because there are differences in cytotoxic reactions between molecular targeted drugs such as imatinib and anticancer agents over time.

In this study, we need to select the some type of cell lines in order to determine the difference of cell reaction profile against anticancer reagents in real-time using RTCA system. Non-invasive SQUU-A cell line and invasive SQUU-B cell line which were established from local recurrent tongue cancer tumors in a single patient, were selected because we were engaged in research on metastasis of SQUU-B cell line using SQUU-A cell line and SQUU-B cell line (10-12). SAS cell line 
were established from poorly differentiated human squamous cell carcinoma of the tongue (13). NA cell line was established as a fibronectin-producing cell line (14). Furthermore, it has been reported that the cytotoxicity of anti-cancer reagents in OSCC has been evaluated in SQUU-A cell line and SQUU-B cell line (15), SAS cell line (16), NA cell line (17) using various conventional methods. That is why, we selected four these cell lines with each characteristic feature in the present study, which were also used in cytotoxic assay in previous study.

In this study, we focused on a new RTCA device developed for real-time measurement and evaluated the $\mathrm{IC}_{50}$ values as a scale to assess the cytotoxicity of four anticancer agents towards in four OSCC cell lines. This allowed us to obtain information about the variations observed between the different anticancer reagents and cell lines in real-time.

The aim of the present study was to obtain $\mathrm{IC}_{50}$ profiles from immediately after addition of anticancer agents using an RTCA system. This study demonstrated the advantage of evaluating the cytotoxicity of anticancer agents using an RTCA system compared with an endpoint assay.

\section{Materials and methods}

Reagents and materials. 5-Fluorouracil (5-FU) was diluted to $100 \mathrm{mM}$ in dimethylsulfoxide (DMSO; Sigma-Aldrich Inc., St. Louis, MO, USA). Doxifluridine and carboplatin were diluted to 100 and $50 \mathrm{mM}$, respectively, in distilled water. Docetaxel was diluted to $10 \mathrm{mM}$ in ethanol. All anticancer reagents were sourced from Wako Pure Chemical Industries, Ltd., (Osaka, Japan) and stored at $-20^{\circ} \mathrm{C}$.

Cell culture. Human OSCC cell lines SQUU-A, SQUU-B, SAS, and NA were derived from human tongue samples. SQUU-A and SQUU-B, were kindly provided by Morifuji-Wilson M (Kumamoto University, Kumamoto, Japan), were established from local recurrent tongue cancer tumors (18). SAS $(13,19,20)$ was purchased from the Riken BRC Cell Bank (Tsukuba, Japan). NA (14) was kindly provided by Dr. Jun-ichi Iwata (Kyushu University; Fukuoka, Japan). All cell lines were maintained in Dulbecco's modified Eagle's medium (DMEM; Nacalai Tesque, Inc., Kyoto, Japan) containing 10\% fetal calf serum (Biowest, Nuaille, France) at $37^{\circ} \mathrm{C}$ in a humidified atmosphere with $5 \% \mathrm{CO}_{2}$.

Measurement of OSCC cell proliferation by the RTCA cytotoxicity assay. CI was acquired by the iCELLigence system (ACEA Biosciences, Inc., San Diego, CA, USA) as the RTCA system. All monitoring was performed at $37^{\circ} \mathrm{C}$ with regulated $\mathrm{CO}_{2}$ content (5\%). E-plates (culture plates for the iCELLigence system) containing $200 \mu \mathrm{l}$ culture medium per well were equilibrated to $37^{\circ} \mathrm{C}$, and CI was set to zero under these conditions. Cells $\left(2 \times 10^{4}\right.$ cells/well unless specified otherwise) were added in $560 \mu \mathrm{l}$ culture medium Anticancer agents were added at $24 \mathrm{~h}$ after seeding the cells. The CI was monitored in real-time for $96 \mathrm{~h}$ after cell seeding. The $\mathrm{IC}_{50}$ values were calculated by RTCA Data Analysis Software version 1.0 (ACEA Biosciences, Inc.).

Eight points concentration of four anticancer reagents were set based on $\mathrm{C}_{\max }$ values in previous study (21-25). Furthermore, time points were set during $72 \mathrm{~h}$ including $24 \mathrm{~h}$ and $48 \mathrm{~h}$, which were general method to evaluate cytotoxicity in end-point assay.

Curve fitting of the $I_{50}$ data. We used the following sigmoidal dose-response formula to calculate the $\mathrm{IC}_{50}$ values: $\mathrm{Y}=\mathrm{Low}$ $\mathrm{CI}+($ High CI-Low $\mathrm{CI}) /\left\{1+10 \wedge\left(\log \mathrm{IC}_{50}-\mathrm{X}\right)\right\}$, where 'Low CI' represents the minimum CI values, 'High CI' represents the maximum cell index values, $\mathrm{Y}$ is the cell index, and $\mathrm{X}$ is the $\log$ of concentration (M).

Measurement of OSCC cell proliferation by the WST-8 assay. After the initial seeding and culture of OSCC cells, the culture medium was removed and replaced with anticancer agent-containing medium. After 24,48 , and $72 \mathrm{~h}$ of incubation, $20 \mu$ l WST-8 dye (Cell Counting Kit-8; Dojindo Corporation, Tokyo, Japan) was added to each well. After $3 \mathrm{~h}$, the plates were read at $450 \mathrm{~nm} / 655 \mathrm{~nm}$. The cell survival rate was calculated using the formula below (7). $\mathrm{IC}_{50}$ values were calculated by linear approximation regression of the percentage survival versus the drug concentration.

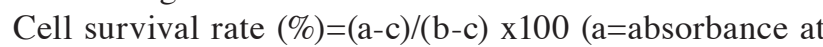
each concentration of the anticancer reagent, $b=$ absorbance at $0 \mu \mathrm{M}$ of the anticancer reagent, and $\mathrm{c}=$ absorbance of the blank).

Statistical analysis. All data are shown as the mean \pm standard deviation (SD) of three independent experiments. Correlations between $\mathrm{IC}_{50}$ values obtained using the RTCA system and WST- 8 assay were evaluated for statistical significance by the Spearman test. Two-tailed values of $\mathrm{P}<0.05$ were considered as significant.

\section{Results}

Effect of the anticancer agent concentration on OSCC cell proliferation using the RTCA system. We evaluated the cytotoxicity of four anticancer reagents (5-FU, doxifluridine, carboplatin, and docetaxel) in four OSCC cell lines by monitoring the CI values for $96 \mathrm{~h}$ after the cells were seeded at $2 \times 10^{4}$ cells/well on E-plates (Figs. 1-4). The CI values were decreased in a dose-dependent manner in all four OSCC cell lines. Therefore, the reduction in CI values correlated with the decrease in cell number. As shown in Fig. 2, the CI value for invasive SQUU-B cell line was lower than those of other OSCC cells. As shown in Fig. 3, CI profile obtained for SAS cell line showed delayed increase after $48 \mathrm{~h}$. As shown in Fig. 4, the rate of proliferation and max CI value in NA cell line were higher than one of other cell lines.

Real-time measurement of the $I C_{50}$ profiles of anticancer agents in OSCC cells using the RTCA system. The $\mathrm{IC}_{50}$ profiles of the four anticancer reagents in the four OSCC cell lines were determined by the RTCA system and calculated by the commercial software provided with the instrument (a subset of the SQUU-B data are shown in Fig. 5). The $\mathrm{IC}_{50}$ values were plotted for $72 \mathrm{~h}$ after the addition of anticancer agents. The $\mathrm{IC}_{50}$ values at 24, 48, and $72 \mathrm{~h}$ for all four cell lines are summarized in Tables I-IV. As shown in Fig. 5, there was time lag in the cytotoxic reactions of 5-FU (Fig. 5A) and docetaxel (Fig. 5D), and recovery of cell proliferation was observed at 
A $5-\mathrm{FU}$

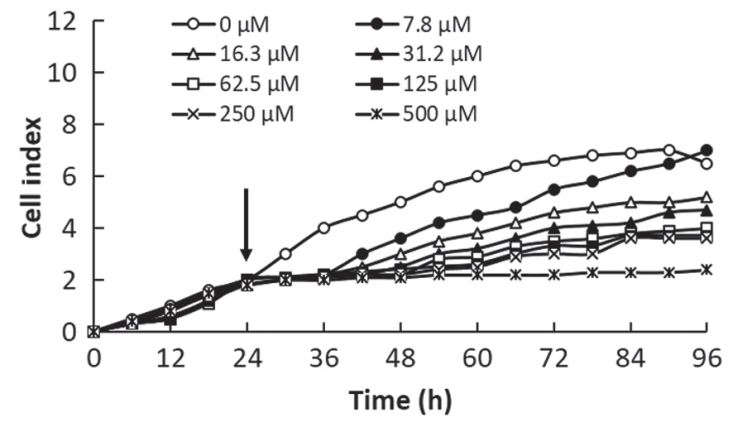

C Carboplatin

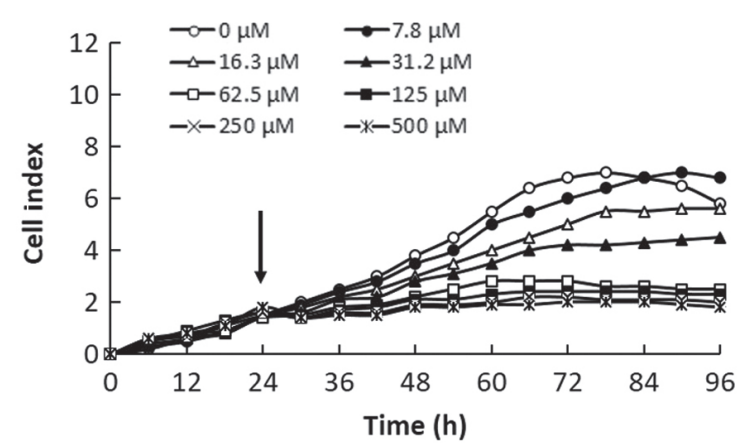

B Doxifluridine

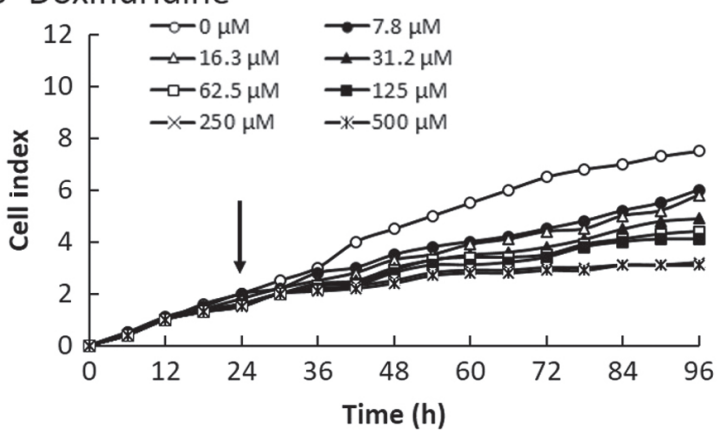

D Docetaxel

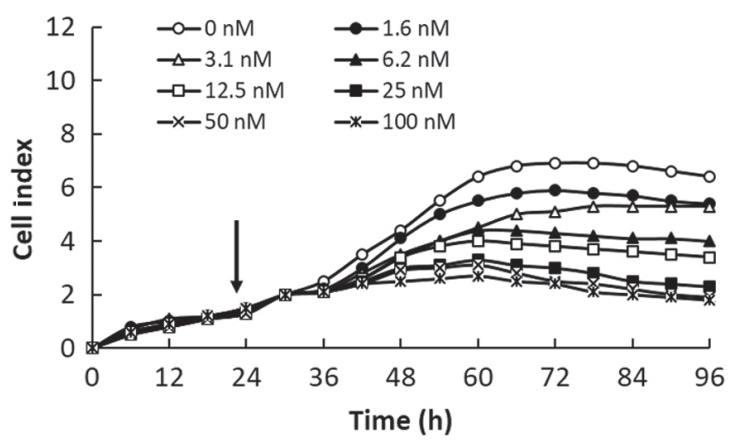

Figure 1. CI measurements of the SQUU-A cell line treated with four anticancer agents. (A) 5-FU, (B) doxifluridine, (C) carboplatin, and (D) docetaxel. Data are represented as the mean $\pm \mathrm{SD}(\mathrm{n}=3)$ though the $\mathrm{SD}$ values were too small to see. Black arrows indicate the time of addition of anticancer agents. CI, cell index; 5-FU, 5-fluorouracil.

A 5 -FU

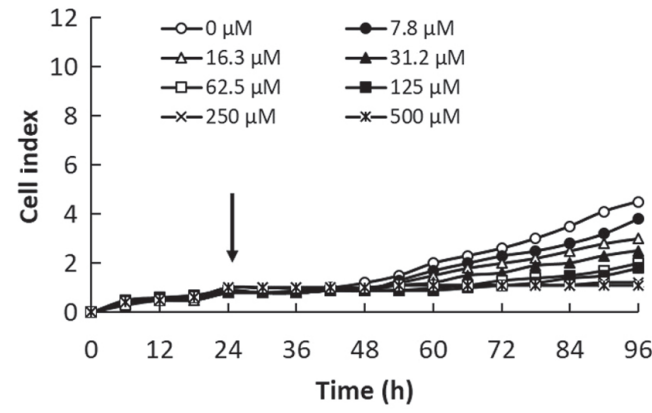

C Carboplatin

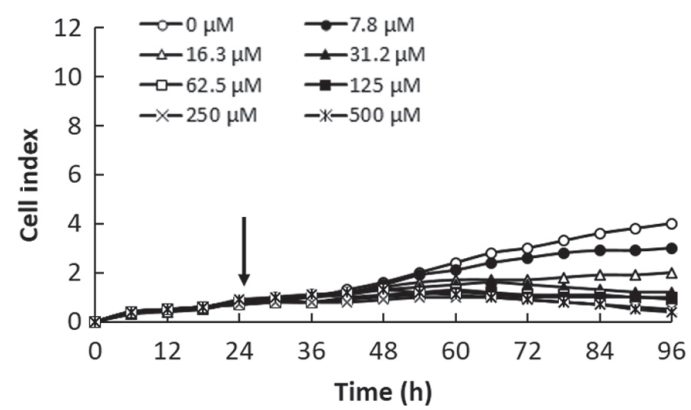

B Doxifluridine

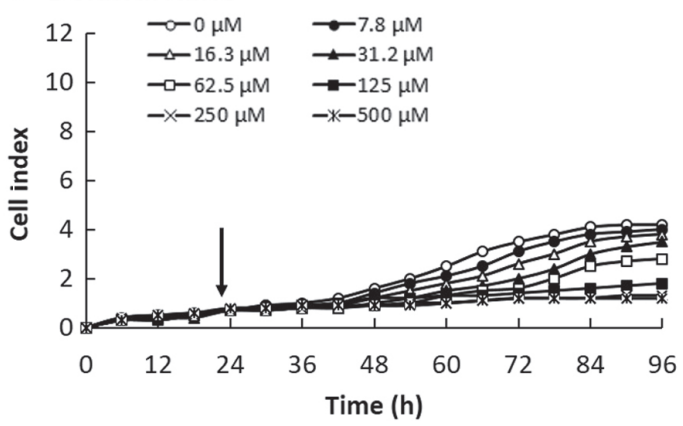

D Docetaxel

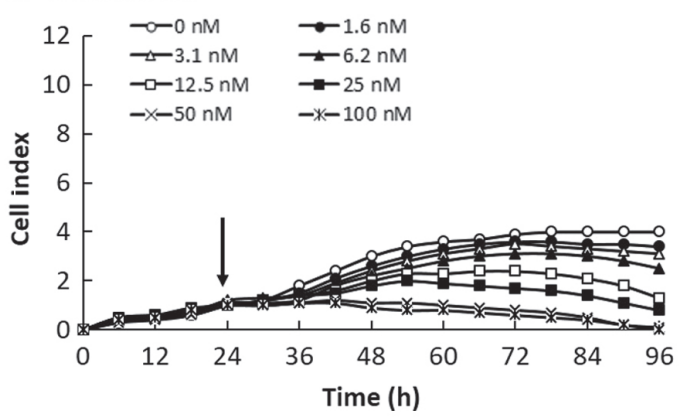

Figure 2. CI measurements of the SQUU-B cell line treated with four anticancer agents. (A) 5-FU, (B) doxifluridine, (C) carboplatin, and (D) docetaxel. Data are represented as the mean $\pm \mathrm{SD}(\mathrm{n}=3)$ though the $\mathrm{SD}$ values were too small to see. Black arrows indicate the time of addition of the anticancer reagents. CI, cell index; 5-FU, 5-fluorouracil.

about $24 \mathrm{~h}$ after treatments. However, cytotoxic reactions were observed immediately after treatment with anticancer agents such as doxifluridine (Fig. 5B) and carboplatin (Fig. 5C).
Dose-response curves in SQUU-B cell line using RTCA system were shown in supplemental materials (Figs. S1-S4) in order to show how to conversion the data of Fig. 2 into Fig. 5. 


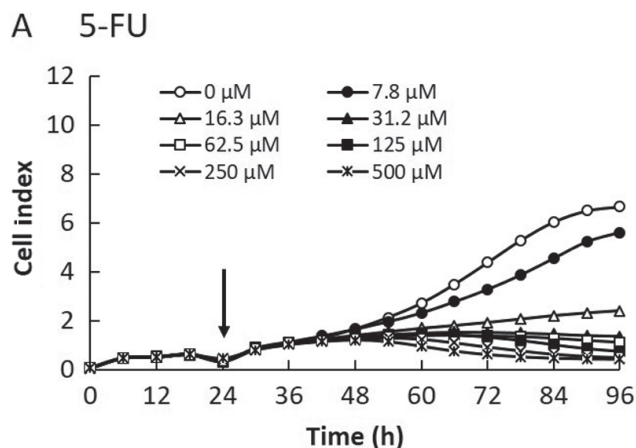

C Carboplatin

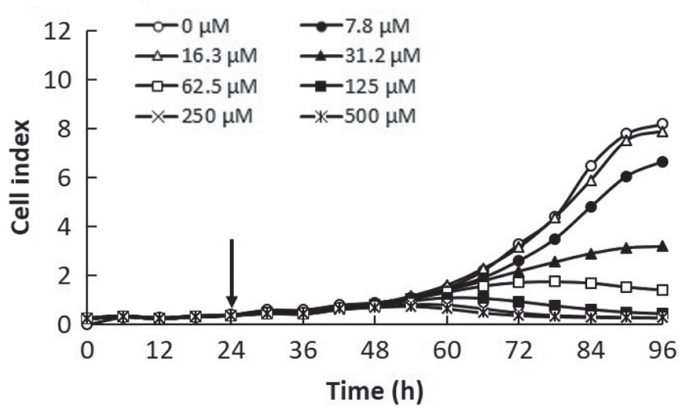

B Doxifluridine

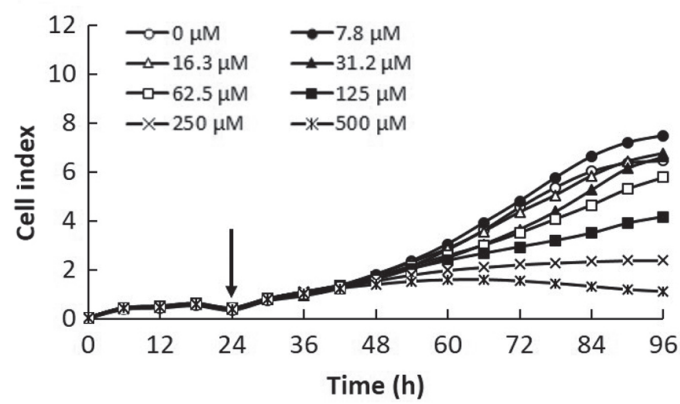

D Docetaxel

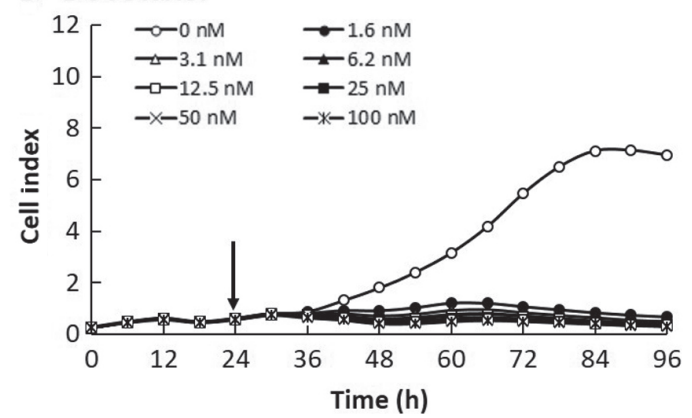

Figure 3. CI measurements of the NA cell line treated with four anticancer agents. (A) 5-FU, (B) doxifluridine, (C) carboplatin and (D) docetaxel. Data are represented as the mean $\pm \mathrm{SD}(\mathrm{n}=3)$ though the $\mathrm{SD}$ values were too small to see. Black arrows indicate the time of addition of the anticancer reagents. CI, cell index; 5-FU, 5-fluorouracil.

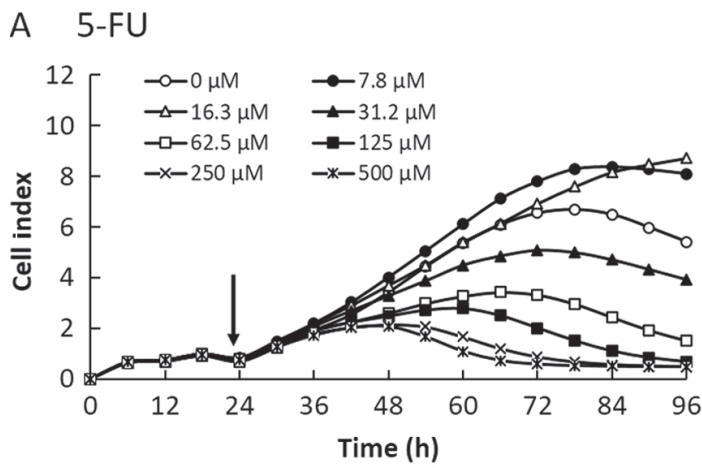

C Carboplatin

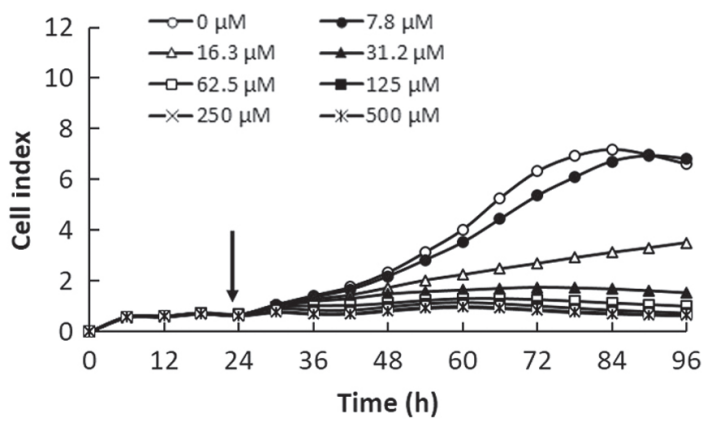

B Doxifluridine

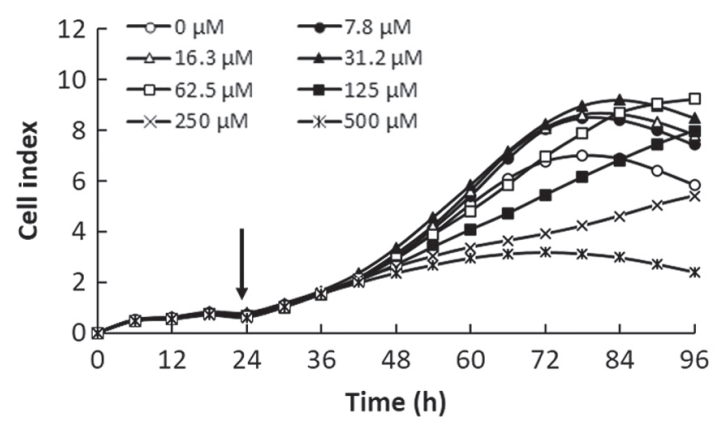

D Docetaxel

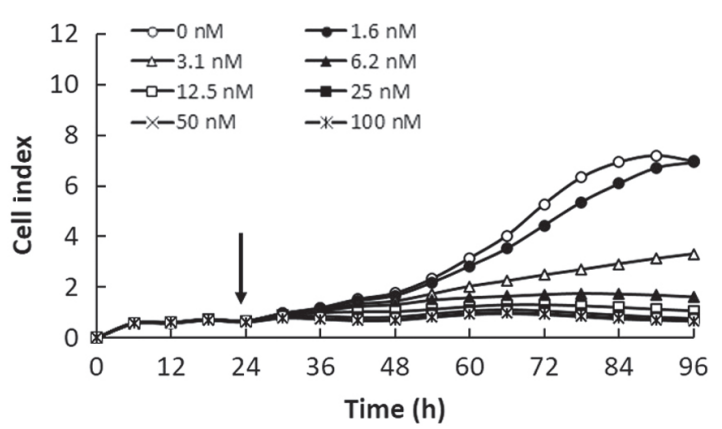

Figure 4. CI measurements of the SAS cell line treated with four anticancer reagents. (A) 5-FU, (B) doxifluridine, (C) carboplatin, and (D) docetaxel. Data are represented as the mean $\pm \mathrm{SD}(\mathrm{n}=3)$ though the $\mathrm{SD}$ values were too small to see. Black arrows indicate the time of addition of the anticancer reagents. CI, cell index; 5-FU, 5-fluorouracil.

While, cell viability curves of SQUU-B using WST-8 assay were also shown in supplemental materials (Figs. S5-S8). $\mathrm{R}^{2}$ values at $72 \mathrm{~h}$ after addition anticancer reagents in WST-8 assay were low in four anticancer reagents compared with one of $24 \mathrm{~h}$ and $48 \mathrm{~h}$. These results showed that it is desirable that end-point assay be performed at $24 \mathrm{~h}$ or $48 \mathrm{~h}$ to be used as a general 

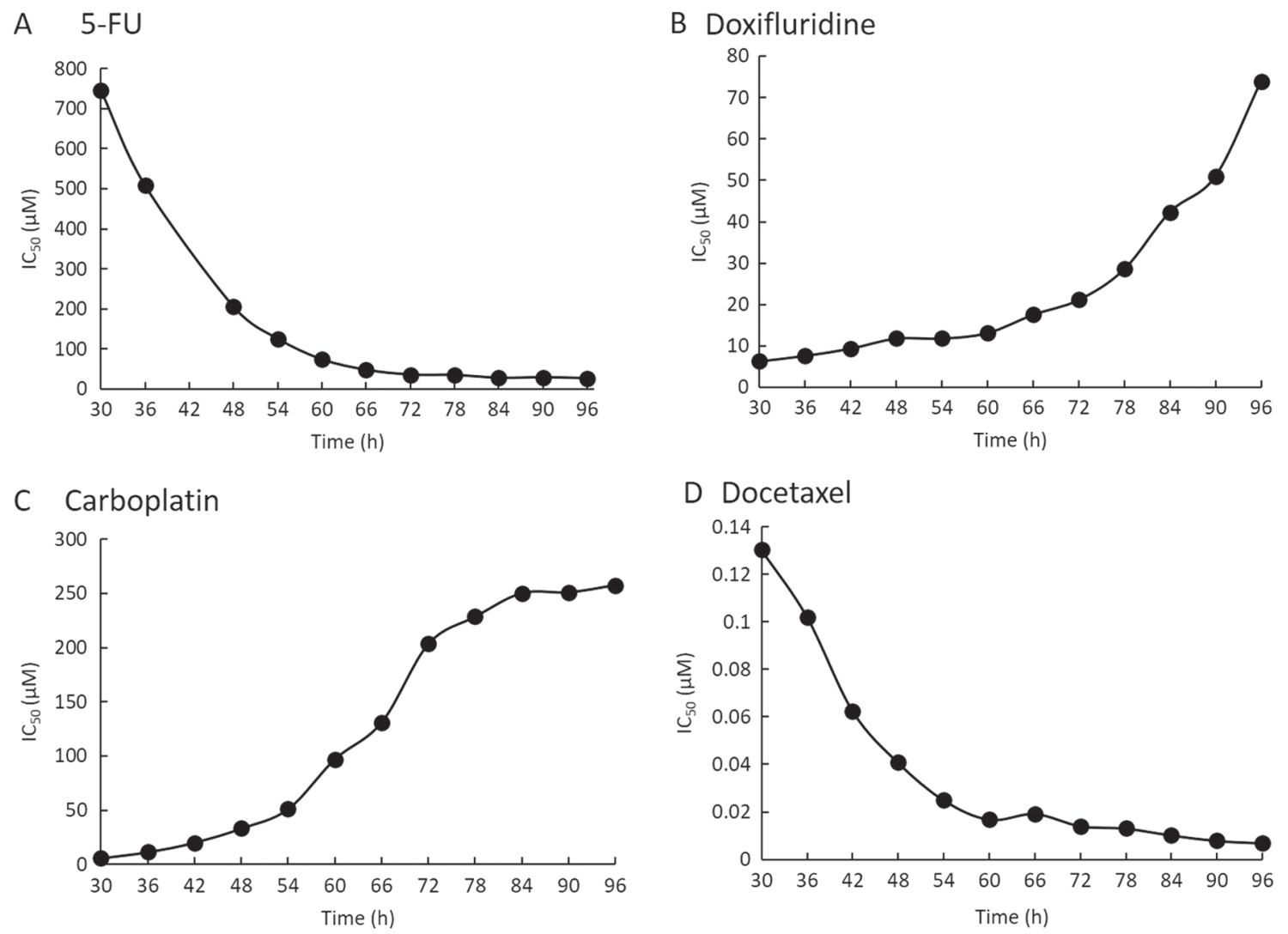

Figure 5. Real-time $\mathrm{IC}_{50}$ profiles of the SQUU-B cell line after treatment with four anticancer reagents. The results of 5-FU, doxifluridine, carboplatin, and docetaxel are shown in (A-D), respectively. Data are represented as the mean $\pm \mathrm{SD}(\mathrm{n}=3)$ though the $\mathrm{SD}$ values were too small to see. CI, cell index; 5-FU, 5-fluorouracil.

protocol. In this study, the cell viability curves of WST-8 assay were shown in supplemental materials because there were no novelty in how to calculation of $\mathrm{IC}_{50}$ values using WST-8 assay.

Correlations between real-time measurements of $I C_{50}$ values using the RTCA system and endpoint measurements of $I_{50}$ values using the WST-8 assay in OSCC cells. As shown in Fig. $6, \mathrm{IC}_{50}$ values at 24,48 , and $72 \mathrm{~h}$ using two methods were plotted. The horizontal axis shows real-time $\mathrm{IC}_{50}$ values measured using the RTCA system, while the longitudinal axis shows endpoint $\mathrm{IC}_{50}$ values measured using the WST-8 assay. A positive correlation was observed between the two types of assay method to measure the $\mathrm{IC}_{50}$ for each anticancer agent. The results of 5-FU, doxifluridine, carboplatin, and docetaxcel were $y=8.19 x+346.02\left(R^{2}=0.94, r s=0.66,{ }^{*} \mathrm{P}<0.05\right)$, $y=1.00 x+172.70\left(R^{2}=0.91, r \mathrm{~s}=0.82,{ }^{* *} \mathrm{P}<0.01\right), y=1.90 x+206.81$ $\left(R^{2}=0.92, r \mathrm{~s}=0.96,{ }^{* *} \mathrm{P}<0.01\right)$, and $y=13.53 x+0.08\left(R^{2}=0.95\right.$, $\left.r \mathrm{~s}=0.73,{ }^{*} \mathrm{P}<0.05\right)$, respectively. The real-time $\mathrm{IC}_{50}$ values tended to be lower than the corresponding endpoint $\mathrm{IC}_{50}$ values.

\section{Discussion}

CI values calculated by the RTCA are also representing the cell status (3). As shown in Figs. 1-5, SD values of CI values were too small to see. For example, all SD values in Fig. 1 were under 0.05. The reason for low CI values of SQUU-B was suggested that the adhesion protein E-cadherin plays an essential role in metastasis, with reduced levels of E-cadherin promoting cell migration and cell invasion (26). The reason for high max CI values of NA was suggested that it has been reported that fibronectin accelerated cell proliferation and adhesion due to the feature of NA cell line as a fibronectin producing cell line (6). Thus, cell reactions of each cell lines against four anticancer reagents were variable. We could not find the causal relationship between $\mathrm{IC}_{50}$ values and the feature of cell lines in this study. However, it is important to detect a cell reaction in real-time as a CI profile to evaluate the cytotoxicity of anticancer reagent when considering pharmaceutical application to human.

The $\mathrm{IC}_{50}$ profile of SQUU-B cell line was described in Fig. 5 as a representative $\mathrm{IC}_{50}$ profile because there were no differences in $\mathrm{IC}_{50}$ profile pattern in same cell line in case of same reagent, though we calculated $\mathrm{IC}_{50}$ values in all cell line using four anticancer reagents. We found that the $\mathrm{IC}_{50}$ profiles varied for each anticancer agent and in each OSCC cell line. As shown in Fig. 5, 5-FU and docetaxel required more than $24 \mathrm{~h}(48 \mathrm{~h}$ in the figure) to start exerting a cytotoxic effect on the OSCC cells, whereas the $\mathrm{IC}_{50}$ values had recovered from about $24 \mathrm{~h}$ (48 $\mathrm{h}$ in the figure) after the addition of doxifluridine and carboplatin. Thus, we suggested that the differences of real-time $\mathrm{IC}_{50}$ profiles was caused by anticancer reagent. Such observations would not have been possible without real-time measurement using the RTCA. Real-time monitoring of the $\mathrm{IC}_{50}$ values also revealed that these values changed markedly over time. There is the possibility of not detecting changes using conventional methods, because only one time point of 
Table I. $\mathrm{IC}_{50}$ values of 5-FU determined with the RTCA system after 48, 72, and $96 \mathrm{~h}$ incubation in OSCC cells.

\begin{tabular}{|c|c|c|c|c|c|c|}
\hline \multirow[b]{2}{*}{ Cell line } & \multicolumn{2}{|c|}{$48 \mathrm{~h}$} & \multicolumn{2}{|c|}{$72 \mathrm{~h}$} & \multicolumn{2}{|c|}{$96 \mathrm{~h}$} \\
\hline & $\mathrm{IC}_{50}(\mu \mathrm{M})$ & $\mathrm{r}^{2}$ & $\mathrm{IC}_{50}(\mu \mathrm{M})$ & $r^{2}$ & $\mathrm{IC}_{50}(\mu \mathrm{M})$ & $\mathrm{r}^{2}$ \\
\hline SQUU-A & 48.2 & 0.99 & 3.3 & 0.99 & 8 & 0.99 \\
\hline SQUU-B & 372 & 0.56 & 46.8 & 0.91 & 27.5 & 0.97 \\
\hline NA & 3 & 0.91 & 3 & 0.94 & 7 & 0.9 \\
\hline SAS & 28 & 0.99 & 36 & 1 & 18 & 0.92 \\
\hline
\end{tabular}

5-FU, 5-fluorouracil; RTCA, real-time cell-monitoring analysis; OSCC, oral squamous cell carcinoma.

Table II. $\mathrm{IC}_{50}$ values of doxifluridine determined with the RTCA system after 48, 72, and $96 \mathrm{~h}$ incubation in OSCC cells .

\begin{tabular}{|c|c|c|c|c|c|c|}
\hline \multirow[b]{2}{*}{ Cell line } & \multicolumn{2}{|c|}{$48 \mathrm{~h}$} & \multicolumn{2}{|c|}{$72 \mathrm{~h}$} & \multicolumn{2}{|c|}{$96 \mathrm{~h}$} \\
\hline & $\mathrm{IC}_{50}(\mu \mathrm{M})$ & $r^{2}$ & $\mathrm{IC}_{50}(\mu \mathrm{M})$ & $r^{2}$ & $\mathrm{IC}_{50}(\mu \mathrm{M})$ & $r^{2}$ \\
\hline SQUU-A & 59.9 & 0.99 & 593 & 0.99 & 696 & 0.99 \\
\hline SQUU-B & 10.8 & 0.99 & 21.3 & 0.99 & 73.9 & 0.96 \\
\hline NA & 224 & 0.82 & 115 & 0.97 & 232 & 0.99 \\
\hline SAS & 304 & 0.82 & 196 & 0.92 & 83 & 0.87 \\
\hline
\end{tabular}

RTCA, real-time cell-monitoring analysis; OSCC, oral squamous cell carcinoma.

Table III. IC $_{50}$ values of carboplatin determined with the RTCA system after 48, 72, and $96 \mathrm{~h}$ incubation in OSCC cells.

\begin{tabular}{|c|c|c|c|c|c|c|}
\hline \multirow[b]{2}{*}{ Cell line } & \multicolumn{2}{|c|}{$48 \mathrm{~h}$} & \multicolumn{2}{|c|}{$72 \mathrm{~h}$} & \multicolumn{2}{|c|}{$96 \mathrm{~h}$} \\
\hline & $\mathrm{IC}_{50}(\mu \mathrm{M})$ & $r^{2}$ & $\mathrm{IC}_{50}(\mu \mathrm{M})$ & $r^{2}$ & $\mathrm{IC}_{50}(\mu \mathrm{M})$ & $\mathrm{r}^{2}$ \\
\hline SQUU-A & 33.2 & 0.74 & 61.8 & 0.99 & 216 & 0.99 \\
\hline SQUU-B & 25.3 & 0.87 & 187 & 0.96 & 227 & 0.99 \\
\hline NA & 547 & 0.96 & 44 & 0.99 & 30 & 0.89 \\
\hline SAS & 600 & 0.92 & 580 & 0.92 & 351 & 0.81 \\
\hline
\end{tabular}

RTCA, real-time cell-monitoring analysis; OSCC, oral squamous cell carcinoma.

the $\mathrm{IC}_{50}$ after treatment with the anticancer agent is evaluated by an endpoint assay.

The RTCA system is unlike traditional endpoint assays be because the measurement of impedance is non-invasive and can provide high quality, quantitative data on cytotoxicity in a continuous manner. As shown in Fig. 6, there were significant positive correlations between $\mathrm{IC}_{50}$ values obtained with the RTCA system and WST-8 assay, even though there were some differences in absolute values of CI such as low CI values obtained for SQUU-B cell line. These results suggested that even a low CI obtained for some cell lines would be able to evaluate the cytotoxicity high sensitivity in RTCA system. While, the real-time $\mathrm{IC}_{50}$ values were lower than endpoint $\mathrm{IC}_{50}$ values when the real-time $\mathrm{IC}_{50}$ values obtained with the RTCA system were compared with the endpoint $\mathrm{IC}_{50}$ values obtained with the WST-8 assay. These results suggest that the RTCA system can be used to sensitively evaluate the effect of anticancer agents on cell proliferation and adhesion.

In RTCA system, adherent cell act as an insulator on the surface of the electrode and change the ionic medium of the electrode solution, increasing the impedance (27). Thus, CI is function of the cell number and ratio of cells at different time intervals. $\mathrm{CI}=0$ when there is no cell adhesion (5). CI changes described by RTCA system are reflected dynamic phenotype of cell. These dynamic monitoring of cell-drug interaction enables us to obtain a better understanding of temporal effects in vitro, especially immediately after treatment with drug (28). The kinetic feature of the cells offers insightful information that cannot be acquired from a conventional single end-point assay such as WST-8 assay. While, results 
Table IV. $\mathrm{IC}_{50}$ values of docetaxel determined with the RTCA system after 48, 72 and $96 \mathrm{~h}$ incubation in OSCC cells.

\begin{tabular}{|c|c|c|c|c|c|c|}
\hline \multirow[b]{2}{*}{ Docetaxel } & \multicolumn{2}{|c|}{$48 \mathrm{~h}$} & \multicolumn{2}{|c|}{$72 \mathrm{~h}$} & \multicolumn{2}{|c|}{$96 \mathrm{~h}$} \\
\hline & $\mathrm{IC}_{50}(\mathrm{nM})$ & $r^{2}$ & $\mathrm{IC}_{50}(\mathrm{nM})$ & $r^{2}$ & $\mathrm{IC}_{50}(\mathrm{nM})$ & $\mathrm{r}^{2}$ \\
\hline SQUU-A & 27.3 & 0.96 & 5.4 & 0.96 & 3.1 & 0.95 \\
\hline SQUU-B & 58.1 & 0.99 & 16 & 0.98 & 6.9 & 0.93 \\
\hline NA & 1 & 0.99 & 0.9 & 0.98 & 0.8 & 0.99 \\
\hline SAS & 3 & 0.99 & 2 & 0.92 & 2 & 0.92 \\
\hline
\end{tabular}

RTCA, real-time cell-monitoring analysis; OSCC, oral squamous cell carcinoma.

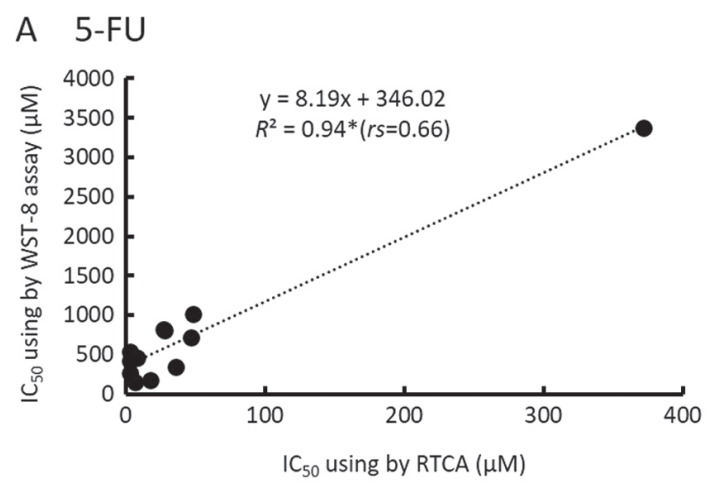

B Doxifluridine
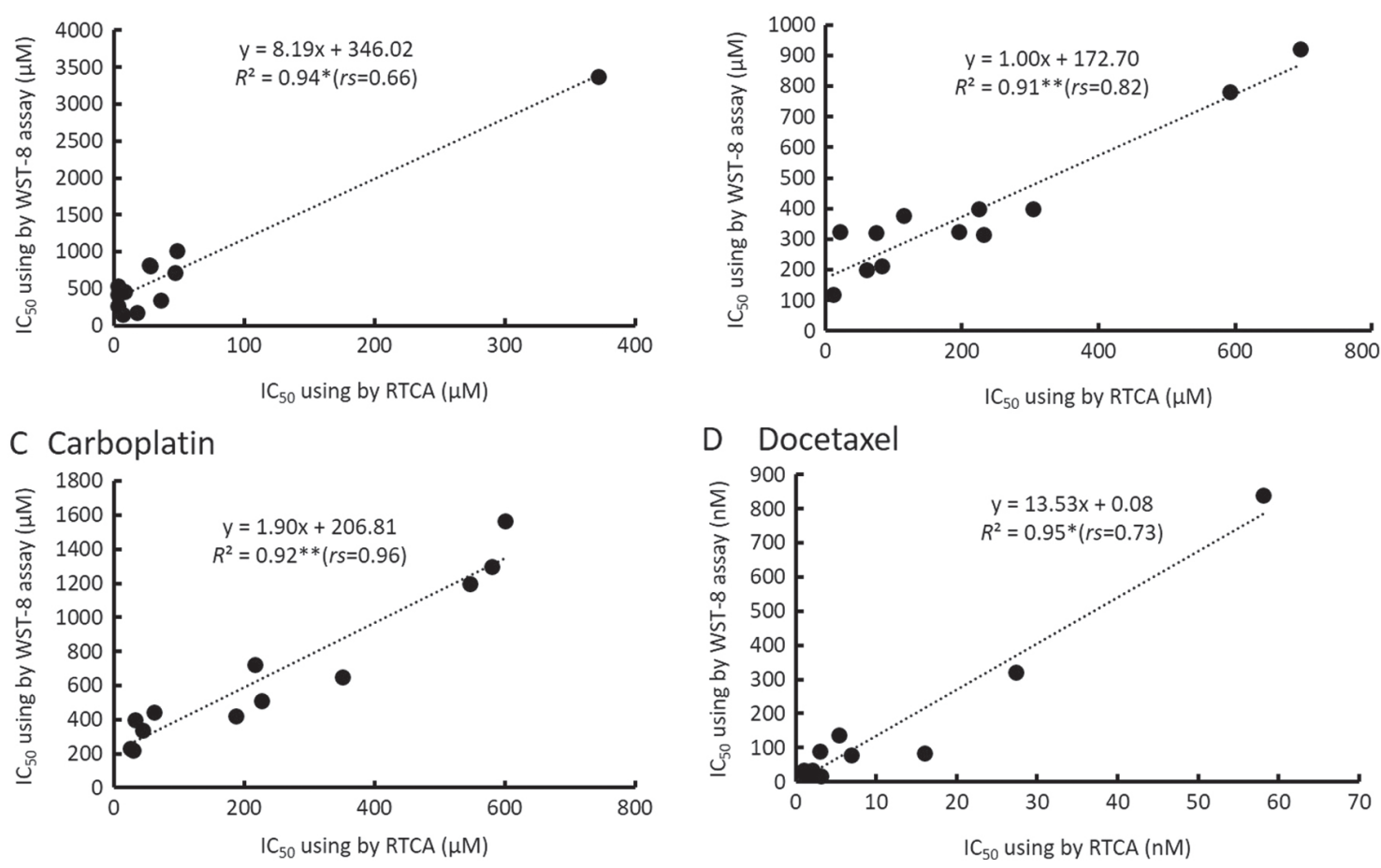

Figure 6. Correlations between real-time measurements of $\mathrm{IC}_{50}$ values using the RTCA system and endpoint measurements of $\mathrm{IC}_{50}$ values using the WST-8 assay in OSCC cells. The average $\mathrm{IC}_{50}$ values at 24,48 , and $72 \mathrm{~h}$ after treatment with anticancer agents in the four OSCC cell lines (12 points) were plotted. The results of 5-FU, doxifluridine, carboplatin, and docetaxel are shown in (A-D), respectively. OSCC, oral squamous cell carcinoma; RTCA, real-time cell analysis.

of WST-8 assay is reflected metabolic reaction of survival cell (29). Toxicity using WST-8 assay might be underestimated if cell metabolic reaction were remained though dynamic cell reaction was occurred. We suggested that these differences of principal in two methods were induced a huge differences of $\mathrm{IC}_{50}$ value up to 8 times between two methods as shown in Fig. 6A. Our previous study reported that $\mathrm{IC}_{50}$ of imatinib in SQUU-A cells calculated by RTCA system and WST- 8 assay were $4 \mu \mathrm{M}$ and $60 \mu \mathrm{M}$, respectively (sensitivity of 15 times) $(6,7)$. Other research groups reported that $\mathrm{IC}_{50}$ of cisplatin in HK-2 cells calculated by RTCA system and WST- 8 assay were $0.76 \mu \mathrm{M}$ and $25 \mu \mathrm{M}$, respectively (sensitivity of 33 times) $(30,31)$. These previous data supported our data to show validity.

It is important to obtain measurements from immediately after treatment with anticancer agents to assess both the side effects of the agents and its desired effects. However, there are few reports of useful methods that correlate in vitro data with human in vivo data. We considered that real-time measurement using the RTCA system would benefit evaluation of the side effects of anticancer agents in normal cells.

Previously reported $\mathrm{C}_{\max }$ values of 5-FU, doxifluridine, carboplatin, and docetaxel are 60 (21), 40-800 (22), 40 (23), and $2 \mu \mathrm{M}(24,25)$, respectively, when used for intravenous treatment in humans. Our data correlated with the human data because the $C_{\max }$ values were included in the range of the experimental doses used in this study.

RTCA systems are the new principal device to evaluate cytotoxicity, which employ the impedance intensity of cell adhesion and not enzyme activity in target cells such as the MTT assay. $\mathrm{IC}_{50}$ values of anticancer agents calculated by the RTCA system were significantly correlated with $\mathrm{IC}_{50}$ levels calculated by the 
conventional endpoint assay. Furthermore, the RTCA system obtained measurements automatically in real-time from immediately after treatment with anticancer agents.

Actually, RTCA system cannot evaluate directly concrete cytotoxicity such as cell death or apoptosis and so on, because cell index were calculated based on impedance. That is why, the combination assay between RTCA system and cell death measurement might be effective method in case of evaluation of concrete cell reaction such as cell death or apoptosis precisely. For example, Annexin V staining or expression of caspase-3 assay for detection of apoptosis, Lactate Dehydrogenase (LDH) release assay for detection of cell death might be effective methods $(32,33)$. Furthermore, it might be useful to evaluate expression of inflammatory protein in the normal cells for detection of side effect when anti-cancer reagent was added to the normal cells seeded on E-plate. Dynamic real-time monitoring during cell culture including anticancer reagents can provide valuable insights for the early detection of therapeutic efficiency and side effect, which cannot evaluate in conventional methods in end-point assay. So, $\mathrm{IC}_{50}$ value calculated by RTCA system might be useful parameter for such as screening from a standpoint of real-time measurement in automated, avoidance of colorimetrically problems or contamination. Furthermore, RTCA system allows the analysis of the whole period of the experiment and does not require the labeling that can negatively affect cell culture experiments.

The novelty of this study is that RTCA system could detect cytotoxicity high sensitivity compared with a conventional method, WST-8 assay. Furthermore, RTCA system could evaluate $\mathrm{IC}_{50}$ value preciously in real-time without restriction of experimental period for at least $72 \mathrm{~h}$ after addition of anticancer reagents.

In conclusion, our results demonstrated that RTCA systems are useful to assay cytotoxicity and could be used in future development of chemotherapeutic agents using cancer cells and evaluation of their side effects in normal cells. Additionally, an RTCA system can be used to evaluate the cell reaction profiles, such as combined therapy and antibody-cell or drug-drug interactions, of anticancer reagents.

\section{Acknowledgements}

Not applicable.

\section{Funding}

No funding was received.

\section{Availability of data and materials}

The datasets used and/or analyzed during the present study are available from the corresponding author on reasonable request.

\section{Authors' contributions}

$\mathrm{MH}$ and $\mathrm{MN}$ conceived and designed the study. $\mathrm{MH}$ and $\mathrm{TN}$ performed the experiments and acquired the data. $\mathrm{MH}$ analyzed the data, prepared the figures and drafted the manuscript. MH, TKY and MN interpreted the results. MH and TKY edited and revised the manuscript. All authors have read and approved the final manuscript.

\section{Ethics approval and consent to participate}

Not applicable.

\section{Patient consent for publication}

Not applicable.

\section{Competing interests}

The authors declare that they have no competing interests.

\section{References}

1. Xing JZ, Zhu L, Jackson JA, Gabos S, Sun XJ, Wang XB and $\mathrm{Xu} \mathrm{X}$ : Dynamic monitoring of cytotoxicity on microelectronic sensors. Chem Res Toxicol 18: 154-161, 2005.

2. Xing JZ, Zhu LJ, Gabos S and Xie L: Microelectronic cell sensor assay for detection of cytotoxicity and prediction of acute toxicity. Toxicol In Vitro 20: 995-1004, 2006.

3. Zhu J, Wang X, Xu X and Abassi YA: Dynamic and label-free monitoring of natural killer cell cytotoxic activity using electronic cell sensor arrays. J Immunol Methods 309: 25-33, 2006.

4. XiB, Yu N, Wang X, Xu X and Abassi YA: The application of cell-based label-free technology in drug discovery. Biotechnol J 3: 484-495, 2008.

5. Türker Sener L, Albeniz G, Dinc B and Albeniz I: iCELLigence real-time cell analysis system for examining the cytotoxicity of drugs to cancer cell lines. Exp Ther Med 14: 1866-1870, 2017.

6. Morioka M, Hazekawa M, Kawakubo-Yasukochi T, Nishinakagawa T, Nakamura S and Nakashima M: Effect of collagen type I or human fibronectin on imatinib cytotoxicity in oral squamous cell carcinoma. Pharmacol Pharm 7: 255-263, 2016.

7. Hazekawa M, Morioka M, Nishinakagawa T, KawakuboYasukochi T, Nakamura S and Nakashima M: Assessment of cytotoxicity of imatinib for oral squamous cell carcinoma by a real-time cell analysis system. eJBio 13: 56-62, 2017.

8. McEneny-King A, Edginton AN and Rao PP: Investigating the binding interactions of the anti-Alzheimer's drug donepezil with CYP3A4 and P-glycoprotein. Bioorg Med Chem Lett 25: 297-301, 2015.

9. Ota T, Shinotoh H, Fukushi K, Kikuchi T, Sato K, Tanaka N, Shimada H, Hirano S, Miyoshi M, Arai H, et al: Esyimation of plasma $\mathrm{IC}_{50}$ of donepezil for cerebral acetylcholinesterase inhibition in patients with Alzheimer disease using positron emission tomography. Clin Neurophaemacol 33: 74-78, 2010.

10. Kawakubo-Yasukochi T, Morioka M, Hayashi Y, Nishinakagawa T, Hazekawa M, Kawano S Nakamura S and Nakashima M: The SQUU-B cell line spreads its metastatic properties to nonmetastatic clone SQUU-A from the same patient through exosomes. J Oral Biosci 58: 33-38, 2016.

11. Morioka M, Kawakubo-Yasukochi T, Hayashi Y, Hazekawa M, Nishinakagawa T, Ono K, Kawano S, Nakamura S and Nakashima M: Exosomes from oral squamous carcinoma cell lines, SQUU-A and SQUU-B, define the tropism of lymphatic dissemination. J Oral Biosci 58: 180-184, 2016.

12. Kawakubo-Yasukochi T, Morioka M, Hazekawa M, Yasukochi A, Nishinakagawa T, Ono K, Kawano S, Nakamura S and Nakashima M: miR-200c-3p spreads invasive capacity in human oral squamous cell carcinoma microenvironment. Mol Carcinog 57: 295-302, 2018.

13. Takahashi K, Kanazawa H, Akiyama Y, Tazaki S, Takahara M, Muto T, Tanzaawa $\mathrm{H}$ and Sato K: Establishment and characterization of a cell line (SAS) from poorly differentiated human squamous cell carcinoma of the tongue. J Jpn Stomatol Soc 38: 20-28, 1989.

14. Yoshiya M: A fibronectin-producing cell line established from a human squamous cell carcinoma of the tongue and its characterization. Jpn J Oral Maxillofac Surg 36: 868-880, 1990.

15. Tanaka H, Toyoshima T, Sonoda K, Kitamura R, Sasaguri M, Kawano S, Matsubara R, Goto Y and Nakamura S: Apoptotic function of tumor-associated antigen RCAS1 in oral squamous cell carcinoma. J Transl Med 12: 112, 2014.

16. Chien MH, Chang WM, Lee WJ, Chang YC, Lai TC, Chan DV, Sharma R, Lin YF and Hsiao M: A Fas ligand (FasL)-fused humanized antibody against tumor-associated glycoprotein 72 selectively exhibits the cytotoxic effect against oral cancer cells with a low FasL/Fas ratio. Mol Cancer Ther 16: 1102-1113, 2017. 
17. Takaoka S, Iwase M, Uchida M, Yoshida S, Kondo G, Watanabe H, Ohashi M, Nagumo M and Shintani S: Effect of combining epidermal growth factor receptor inhibitors and cisplatin on proliferation and apoptosis of oral squamous cell carcinoma cells. Int J Oncol 30: 1460-1476, 2007.

18. Morifuji M, Taniguchi S, Sakai H, Nakabeppu Y and Ohishi M: Differential expression of cytokeratin after orthotopic implantation of newly established human tongue cancer cell lines of defined metastatic ability. Am J Pathol 156: 1317-1326, 2000.

19. Hung CM, Chang CC, Lin CW, Ko SY and Hsu YC: Cucurbitacin $\mathrm{E}$ as inducer of cell death and apoptosis in human oral squamous cell carcinoma cell line SAS. Int J Mol Sci 14: 17147-17156, 2013

20. Chen YW, Huang HS, Shieh YS, Ma KH, Huang SH, Hueng DY, Sytwu HK and Lin GJ: A novel compound NSC745885 exerts anti-tumor effect on tongue cancer SAS cells in vitro and in vivo. PLoS One 9: e104703, 2014.

21. Casale F, Canaparo R, Serpe L, Muntoni E, Pepa CD, Costa M, Marirone L, Zara GP, Fornari G and Eandi M: Plasma concentrations of 5-fluorouracil and its metabolites in colon cancer patients. Pharmacol Res 50: 173-179, 2004

22. Van Der Heyden SA, Highley MS, De Bruijin EA, Tjaden UR, Reeuwijk HJ, Van Slooten H, Van Oosterom AT and Maes RA: Pharmacokinetics and bioavailability of oral 5'-deoxy-5-fluorouridine in cancer patients. Br J Clin Pharmecol 47: 351-356, 1999.

23. Kern W, Braess J, Friedrichsen S, Kaufmann CC, Schleyer E and Hiddemann W: Carboplatin pharmacokinetics in patients receiving carboplatin and paclitaxel/docetaxel for advanced lung cancers: Impact of age and renal function on area under the curve. J Cancer Res Clin Oncol 127: 64-68, 2001.

24. Kenmotsu H and Tanigawara Y: Pharmacokinetics, dynamics and toxicity of docetaxel: Why the Japanese dose differs from the western dose. Cancer Sci 106: 497-504, 2015.

25. Minami H, Kawada K, Sasaki Y, Igarashi T, Saeki T, Tahara M, Itoh $\mathrm{K}$ and Fujii $\mathrm{H}$ : Pharmacokinetics and pharmacodynamics of protein-unbound docetaxel in cancer patients. Cancer Sci 97 235-241, 2006.
26. Zhao P, Guo S, Tu Z, Di L, Zha X, Zhou H and Zhang X: Gihl3 induces human epithelial tumor cell migration and invasion via downregulation of E-cadherin. Acta Biochim Biophys Sin (Shanghai) 48: 266-274, 2016.

27. Szulccek R, Bogaard HJ and van Nieuw Amerogen GP: Electric cell-substrate impedance sensing for the quantification of endothelial proliferation, barrier function, and motility. J Vis Exp. Mar 28, 2014

28. Ku M, Kang M, Suh JS and Yang J: Effects for sequential treatment of siAkt and paclitaxel on gastric cancer cell lines. Int J Med Sci 13: 708-716, 2016.

29. Feng Z, Wang Z, Yang M,Zhou L and Bao Y: Polysaccharopeptide exerts immunoregulatory effects via MyD88-dependent signaling pathway. Int J Biol Macromol 82: 201-207, 2016.

30. Genc G, Kilinc V, Bedir A and Ozkaya O: Effect of creatine and pioglitazone on Hk-2 cell line cisplatin nephrotoxicity. Ren Fail 36: 1104-1107, 2014.

31. Ng NS, Wu MJ, Myers SJ and Aldrich-Wright JR: The in vitro renal cell toxicity of some unconventional anticancer phenanthroline-based platinum (II) cpmplexes. J lnorg Biochem 179: 97-106, 2018

32. Ma K, Zhang C, huang MY, Guo YX and Hu GQ: Crosstalk between Beclin-1-dependent autophagy and caspase-dependent apoptosis induced by transhinone IIA in human osteosarcoma MG-63 cells. Oncol Rep 36: 1807-1818, 2016.

33. Augustine D, Rao RS, Anbu J and Chidambara Murthy KN: In vitro cytotoxic and apoptotic induction effect of earthworm coelomic fluid of Eudrilus eugeniae, Eisenia foetida, and Perionyx excavatus on human oral squamous cell carcinoma-9 cell line. Toxicol Rep 6: 347-357, 2019. 